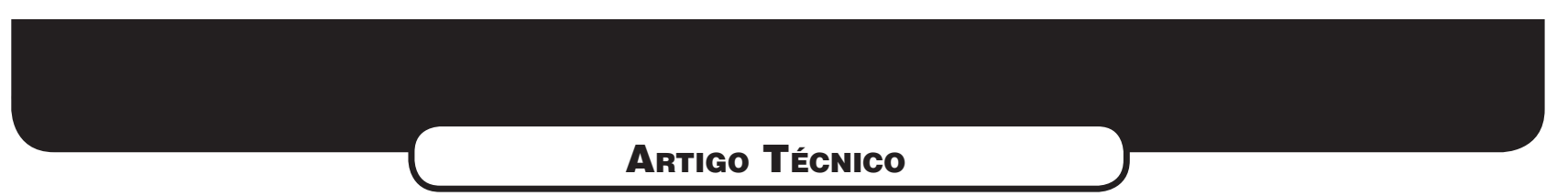

\title{
OS MICRORGANISMOS NAS ATIVIDADES DE DISPOSIÇÃO DE ESGOTOS NO SOLO - ESTUDO DE CASO
}

\section{THE MICRORGANISMS IN THE SEWAGE DISPOSAL IN SOIL - A CASE STUDY}

\section{ADRIANA DE SOUZA CAVINATTO}

Bióloga e mestre em Saúde Pública pelo Departamento de Saúde Ambiental, Faculdade de Saúde Pública da Universidade de São Paulo. Bióloga da CETESB - Companhia de Tecnologia de Saneamento Ambiental

\section{Wanderley da Silva Paganini}

Professor Doutor da Faculdade de Saúde Pública da Universidade de São Paulo - USP. Assistente Executivo da Diretoria de Sistemas Regionais da Companhia de Saneamento Básico do Estado de São Paulo - SABESP

Recebido: 06/06/06 Aceito: 02/01/07

\section{RESUMO}

Este trabalho apresenta os resultados da pesquisa de ovos de helmintos, Salmonella sp, coliformes totais e E. coli no esgoto afluente, efluente e no solo da Estação de Tratamento de Esgotos de Populina (SP), cujo método de tratamento é o escoamento superficial no solo. Os resultados mostraram que o sistema de tratamento foi capaz de reduzir o número de ovos de helmintos presentes no esgoto. O número de organismos encontrados a 50 metros de distância do ponto de aplicação foi menor do que a 20 metros e os mesmos são encontrados em maior número na superfície do solo e a $20 \mathrm{~m}$ de distância do ponto de aplicação dos esgotos. O sistema não foi eficiente na remoção de Salmonella sp., coliformes totais e E. coli. Cabe salientar que a Estação de Tratamento está operando acima da capacidade para a qual foi projetada, o que justificaria tais resultados.

PALAVRAS-CHAVE: Disposição de esgotos no solo, escoamento à superfície, riscos à saúde, contaminação do meio ambiente, microrganismos patogênicos.

\begin{abstract}
This work shows the results of the research of helminthes eggs, Salmonella sp., total coliforms and E. coli in the sewage affluent and effluent and in the soil at the Sewage Treatment Plant in Populina, SP, which treatment method is the overland flow. The results have shown that the system was capable to reduce the number of helminthes eggs in the final effluent and that they are found in a bigger number on the soil surface and in twenty meters from the point of appliance of sewage. It is likely that the humidity has a certain influence on the viability of Ascaris sp. eggs. The system was not efficient on the removal Salmonella sp., total coliform and E. coli. It is worth pointing out that sewage treatment plant is operating over the capacity it was built to operating at, what would justify such results.
\end{abstract}

KEYWORDS: Sewage disposal in soil, overland flow, health risks, environmental contamination, pathogens.

\section{INTRODUÇÃO}

Embora seja mais comum dispor os esgotos e efluentes nos corpos d'água, a disposição no solo é uma alternativa que foi e ainda é empregada de forma muito intensa. Neste caso, dependendo da carga orgânica lançada, o ambiente pode ter condiçóes de receber e decompor os compostos em níveis que não causem danos ao ecossistema local e circunvizinho. Isto porque alguns processos naturais têm condições de promover o tratamento dos esgotos desde que não ocorra sobrecarga e que haja boas condiçóes ambientais que permitam a evolução, reprodução e crescimento de organismos que decompóem e estabilizam a matéria orgânica (Coraucci Filho et al, 1999).

O conjunto formado pelo solo, vegetação superior, energia solar e água asseguram a transformação da matéria orgânica em energia renovável. No sistema solo-microrganismo-planta encontram-se os elementos que atuam no tratamento por disposição no solo: solo e superfície do solo, sistema foliar, colo da planta e sistema radicular. Esses elementos irão atuar com maior ou menor intensidade dependendo do método de disposição adotado (Paganini, 2003).

Os avanços recentes na análise da comunidade do solo, usando métodos moleculares, indicam uma enorme diversidade microbiológica no solo. Essa diversidade excede a dos ambientes aquáticos e é uma grande fonte para a exploração biotecnológica de novos organismos, produtos e processos. $\mathrm{O}$ principal efeito que a diversidade microbiológica pode ter nos processos do ecossistema é assegurar que todos os compostos orgânicos sejam reciclados. Assume-se que a biodiversidade influencie na estabilidade do ecossistema, na produtividade e no poder de recuperação frente a estresses e distúrbios (Torsvik e Ovreas, 2002).

O solo é um sistema complexo que compreende uma variedade de microhabitats com diferentes gradientes físicos e químicos, e condições ambientais descontínuas. Os microrganismos se adaptam aos microhabitats interagindo uns com os outros e com outras partes da biota do solo (Torsvik e Ovreas, 2002). A ação dos microrganismos presentes nos solos não estéreis e nas plantas é um dos principais fatores de remoção de microrganismos patogênicos que chegam com o esgoto ao solo. A ação dos microrganismos na remoção 
de patogênicos tanto é direta por competição vital, como indireta devido às transformações bioquímicas do substrato, principalmente a estabilização (mineralização) da matéria orgânica (Andrade Neto, 1997).

Processos físicos, químicos e biológicos ocorrem no solo provendo um alto nível de tratamento devido a retenção, transformação ou destruição de poluentes (EPA, 1992a). Os principais mecanismos responsáveis pela remoção de microrganismos nos sistemas de tratamento por escoamento superficial no solo incluem sedimentação, filtração pelas camadas orgânicas superficiais e vegetação, adsorção às partículas do solo, predação, irradiação e dessecação durante os períodos de secagem. Geralmente, a eficiência de remoção de patógenos como vírus e organismos indicadores é comparável aos tratamentos secundários convencionais sem cloração (EPA, 1981; Environment Canada, 1984).

As vantagens do tratamento por escoamento superficial no solo são: apresentar condições renováveis de tratamento, evitando, assim, a "exaustão" do sistema solo-planta como depurador; ser apropriado para o tratamento de esgotos de comunidades rurais e indústrias sazonais que geram resíduos orgânicos (indústrias cítricas e usinas de açúcar e álcool); proporcionar um tratamento em nível avançado, com uma operação relativamente simples e de baixo custo; a cobertura vegetal pode ser reaproveitada ou utilizada comercialmente; apresentar a menor restrição quanto às características do meio, necessitando apenas de um solo relativamente impermeável para a sua instalação (EPA, 1992a; Chernicharo, 2001; Paganini, 2003). Algumas desvantagens podem ser a limitação pelo clima, a tolerância da vegetação pela água e a declividade do terreno. A aplicação se restringe a épocas mais quentes $\mathrm{e}$ pode ser limitada quando a temperatura se mantém abaixo do ponto de congelamento e as taxas de aplicação podem estar restritas ao tipo de cultura. Alguns problemas associados a este método estão relacionados à qualidade dos esgotos que podem conter grandes quantidades de sedimento, os quais podem se depositar e entupir os canais de transporte e distribuiçãao (Shuval, 1986; EPA, 1992a).

A prática de disposição de esgotos/efluentes no solo pode envolver riscos de contaminação do meio ambiente e riscos à saúde publica. O solo pode atuar como um vetor e fonte de importantes agentes causadores de doenças humanas, visto que os indivíduos estão em contato permanente com o solo, direta ou indiretamente, via alimento, água e ar (Santamaría e Toranzos, 2003). Os riscos ao meio ambiente envolvem danos e contaminação da vegetação de cobertura, contaminação do solo, do lençol freático e do corpo receptor. Os riscos à saúde pública estão relacionados à contaminação dos trabalhadores rurais ou da estação de tratamento, dos consumidores de produtos vegetais e de produtos animais, os quais tenham pastoreado em terrenos irrigados com esgotos ou efluentes e de populações que residem próximas a estaçôes de tratamento de esgotos ou a áreas agricultáveis. O maior risco à saúde ocorre quando o microrganismo é capaz de sobreviver por grandes períodos de tempo e se movimentar vigorosamente pelo solo.

Neste contexto o presente trabalho se destina a pesquisar os microrganismos nas atividades de disposição de esgotos no solo na Estação de Tratamento de Esgotos de Populina (SP), que adota o método de tratamento por disposição superficial no solo, estando em operação há mais de 20 anos. Estudos desenvolvidos anteriormente nesta planta de tratamento apresentam as características e propriedades do solo na estação, bem como um acompanhamento dos efeitos da disposição de esgotos no solo durante 20 anos de operação do sistema (Paganini, 2001). A partir desse conhecimento, tornou-se possível iniciar novas investigações de campo e pesquisas de microrganismos ainda não estudados como Salmonella $s p$. e Ascaris sp.

Estas pesquisas complementares têm os seguintes objetivos específicos:

- Identificar e quantificar ovos de parasitas intestinais e ovos viáveis de Ascaris sp., no solo, no esgoto bruto e no efluente da Estação de Tratamento de Esgotos de Populina (SP) em relação à distância do ponto de aplicação do esgoto, à profundidade de penetração no solo e ao tempo de secagem do módulo;

- Pesquisar Salmonella sp. no solo e no esgoto afluente e efluente da Estação de Tratamento de Esgotos de Populina $(\mathrm{SP})$, visto que esses organismos ainda não foram pesquisados no sistema;

- Determinar coliformes totais e Escherichia coli no esgoto bruto e no efluente da Estação de Tratamento de Esgotos de Populina (SP), a fim de comparar com estudos já realizados na estação.

\section{METODOLOGIA}

\section{Caracterização da área de estudo}

O município de Populina localizase a noroeste do Estado de São Paulo, na bacia hidrográfica do Rio Turvo - Grande, distando $625 \mathrm{~km}$ da capital do Estado, tendo acesso pela rodovia SP-310 e SP-320, conforme Figura 1 (Paganini, 2001). O município possui uma área de $319 \mathrm{~km}^{2}$. A população total é de 4445 habitantes, sendo a população urbana de 3422 e a rural de 1023 habitantes. A densidade demográfica é de 13,94 habitantes $/ \mathrm{km}^{2}$.

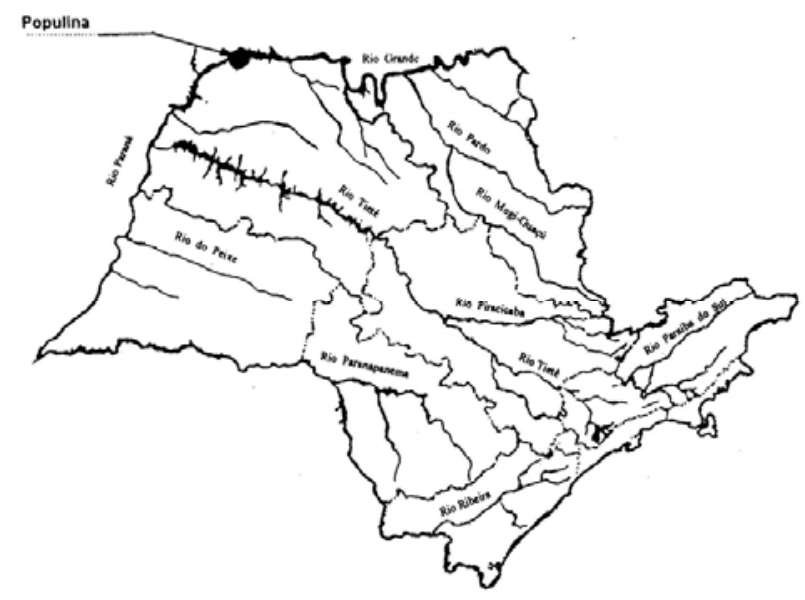

Figura I- Localização do município de Populina no Estado de São Paulo 
Toda a população tem o esgoto tratado por disposição superficial no solo. São 1296 ligaçôes de água e 1173 ligações de esgoto. A temperatura média no município é de $32^{\circ} \mathrm{C}$ nas estaçóes quentes do ano e $24^{\circ} \mathrm{C}$ nas estações mais frias (Paganini 2001; Governo do Estado de São Paulo/SMA 2002).

O sistema está operando acima do limite para o qual foi projetado, ou seja, a planta de tratamento dos esgotos foi projetada em 1983 para uma capacidade de 500 ligaçôes domiciliares e opera hoje com 1173 ligaçōes. Portanto, o tratamento acontece de maneira parcial devido à situação de sobrecarga a partir de 1993. De qualquer forma, a estação de tratamento é um campo de pesquisa ímpar, pois continua recebendo os esgotos brutos do centro urbano ininterruptamente, o que permite avaliar os efeitos da disposição de esgotos ao longo desses anos. O tratamento é constituído por gradeamento, desarenamento, seguidos de quatro módulos de disposição com dimensões individuais de $25 \mathrm{~m}$ de largura por $70 \mathrm{~m}$ de comprimento e $2 \%$ de declividade, configurando-se assim os quatro planos inclinados, nos quais a massa líquida escoa pelo cultivo de gramíneas, onde se efetiva o tratamento propriamente dito.

Em seguida, o efluente é recolhido em canaletas de coleta, dispostas a jusante dos referidos planos inclinados, e encaminhado ao corpo receptor. A estação de tratamento dista $1.200 \mathrm{~m}$ do centro urbano e lança seus efluentes no córrego Vista Alegre, conforme mostra a Figura 2 (Paganini, 1997; Terada et al, 1985).

Cada módulo recebe esgotos por um dia, permanecendo três dias em secagem. O período em que o solo permanece sem receber esgotos foi definido como tempo de descanso do módulo.

A taxa de aplicação, definida como sendo a vazão distribuída por unidade de largura dos módulos, é de $0,7432 \mathrm{~m}^{3} /$ hora $\mathrm{x}$ e a taxa de aplicação superficial é de $6,36 \mathrm{~cm} /$ dia.

\section{Plano de amostragem}

O trabalho de campo compreendeu três amostragens, datadas de $01 / 12 / 2003$, $18 / 05 / 2004$ e $12 / 10 / 2004$, nas quais foram coletadas amostras de solo, esgoto bruto e efluente na Estação de Tratamento de Esgotos de Populina (SP) para a pesquisa de ovos e larvas de helmintos, Salmonella sp., coliformes totais e E. coli.

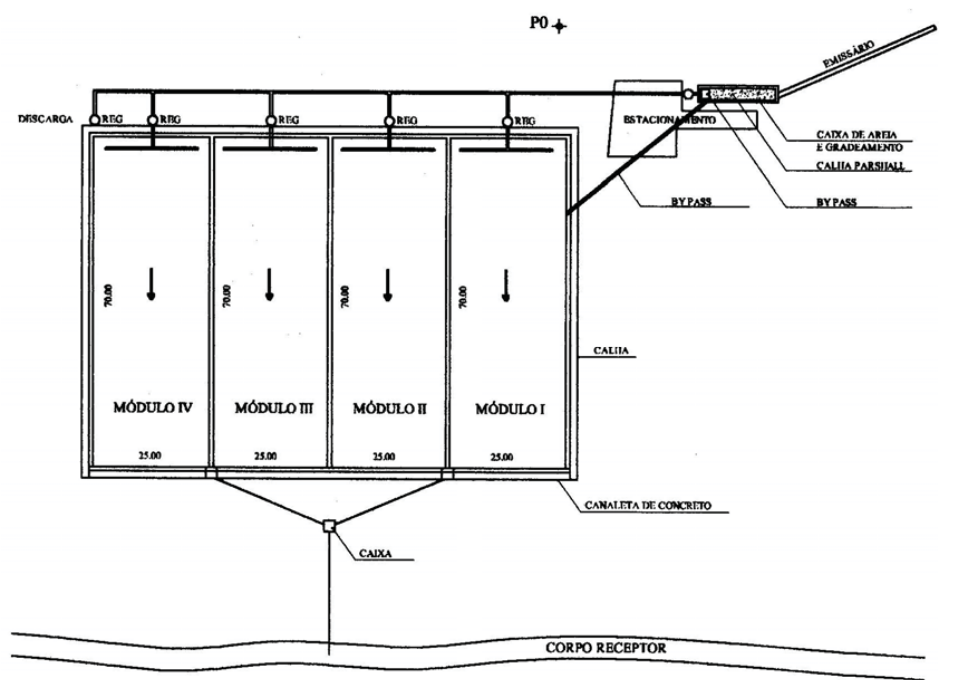

Figura 2- Representação esquemática da Estação de Tratamento de Esgotos de Populina

As amostras foram coletadas em campo, no período da manhã, acondicionadas em sacos plásticos devidamente identificados, e foram mantidas sob baixa temperatura até serem levadas ao laboratório para análises, em um prazo de 24 horas. As análises foram executadas no Laboratório de Microbiologia do Departamento de Saúde Ambiental da Faculdade de Saúde Pública/USP.

Em todas as oportunidades, as amostras líquidas foram coletadas nos módulos que estavam em operação. Em todas as amostragens foram coletadas amostras do esgoto bruto, antes do tratamento, e amostras do efluente final, antes de ser encaminhado ao corpo receptor.

As amostras de solo foram coletadas dentro dos módulos de tratamento e fora dos módulos. Neste caso, foram coletadas amostras de solo fora da estação de tratamento, o qual não recebe esgotos, mas apresenta as mesmas características. Este ponto foi designado como ponto controle (P5). Todas as coletas foram realizadas na superfície ( 0 a 5 centímetros de profundidade) e a 30 centímetros de profundidade. As amostras coletadas dentro dos módulos de tratamento estão descritas na Tabela 1 e ilustradas na Figura 3.

\section{Metodologia adotada para as análises laboratoriais}

a) Ovos de helmintos

Para pesquisa de ovos de helmintos em amostras líquidas (esgoto bruto e efluente), utilizou-se o manual de técnicas parasitológicas e bacteriológicas de laboratório de Ayres e Mara (1997) e o método analítico descrito pela EPA (1992b) para viabilidade. Para a pesquisa de ovos de helmintos em solo, foi utilizado o método analítico descrito pela EPA (1992b).

\section{b) Salmonella sp.}

O isolamento de Salmonella sp. foi efetuado utilizando-se a Norma CETESB L5.218 - Salmonella: Isolamento e Identificação (1993). Para as amostras de solo o procedimento adotado foi a inoculação direta com pré-enriquecimento. As amostras líquidas foram inoculadas diretamente nos meios de enriquecimento caldo selenito novobiocina e caldo Rappaport tetrationato.

\section{c) Coliformes totais e Escherichia coli}

Para a determinação de coliformes totais e Escherichia coli utilizou-se o ensaio cromogênico empregando o Kit Colilert. Os resultados foram expressos em $\mathrm{NMP} / 100 \mathrm{~mL}$ consultando a tabela de NMP fornecido pelo fabricante, em que são dados os limites de confiança de $95 \%$ para cada valor de NMP determinado.

\section{RESULTADOS E DISCUSSÕES}

A finalidade maior das estaçôes de tratamento de esgotos é a de que elas 
Tabela I - Descrição dos pontos de amostragens nas coletas realizadas na Estação de Tratamento de Esgotos (ETE) de Populina (SP)

\begin{tabular}{ccccc}
\hline $\begin{array}{c}\text { Data da } \\
\text { coleta }\end{array}$ & Módulo & $\begin{array}{c}\text { Tempo de descanso } \\
\text { do módulo }\end{array}$ & $\begin{array}{c}\text { Pontos } \\
\text { amostrados }\end{array}$ & $\begin{array}{c}\text { Distância do ponto } \\
\text { de aplicação }\end{array}$ \\
\hline $01 / 12 / 2003$ & I & 1 dia & P1 & $20 \mathrm{~m}$ \\
$18 / 05 / 2004$ & III & 1 dia & P2 & $50 \mathrm{~m}$ \\
$12 / 10 / 2004$ & III & 1 dia & P4 & $20 \mathrm{~m}$ \\
& & & P6 & $50 \mathrm{~m}$ \\
& IV & \multirow{2}{*}{20 dias } & P4 & $20 \mathrm{~m}$ \\
& IV & & P6 & $20 \mathrm{~m}$ \\
& & & P7 & $50 \mathrm{~m}$ \\
\hline
\end{tabular}

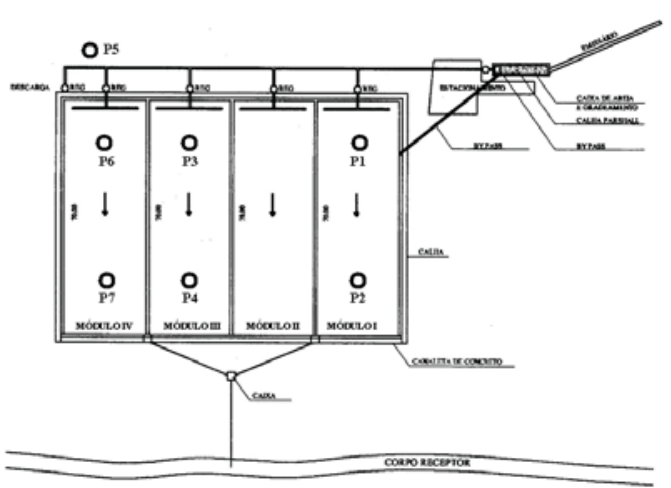

Figura 3 - Pontos de amostragens dentro do
módulo de tratamento e no ponto controle

venham a representar reais barreiras sanitárias destinadas à proteção do meio ambiente à manutenção dos recursos naturais, os quais são finitos. Estas barreiras devem ser perenes e eficientes ao longo da sua vida útil. Entretanto, existem plantas de tratamento concebidas, que são barreiras sanitárias por um determinado período, pois acabam por ter a função de "armazenar" os elementos poluentes, como se fossem depósitos e, quando sua capacidade ou vida útil se esgota, lá estão os problemas, desta feita acumulados e potencializados. Assim, é de suma importância, que as estaçôes de tratamento sejam concebidas de maneira perfeitamente integrada ao ecossistema em que foram locadas, dando destinos definitivos tanto à fase sólida como à fase líquida dos esgotos, de forma que a natureza não sofra impactos irreversíveis, de modo que a planta de tratamento represente solução definitiva, eficiente e eficaz, como devem ser as barreiras sanitárias, inserida no ambiente em que foi construída.

A legislação ambiental vigente é rígida em relação ao lançamento de nutrientes em corpos d'água, apresenta restriçôes $\mathrm{O}$ emprego de processos de tratamento terciários, desenvolvidos para essa finalidade, revelaram que os custos envolvidos crescem exponencialmente com a eficiência obtida nos tratamentos, não tendo sido demonstrada a completa confiabilidade técnica das operações propostas. Além disso, perdura o paradoxo de se considerar os nutrientes contidos nos esgotos como um rejeito, enquanto ampliam-se as extensões de terras áridas e agrava-se a escassez mundial de fertilizantes.

Estas constataçōes têm despertado o interesse para os processos de tratamento de esgotos por disposição de esgotos no solo, tanto para a remoção de cargas poluidoras, como para a fertilização das terras, considerando-a uma alternativa tecnológica viável de polimento, disposição final e também de tratamento de esgotos. De uma só vez, consegue-se a custos bem mais reduzidos, atingir a eficiência pretendida pelos tratamentos convencionais terciários, a utilização dos nutrientes contidos nos esgotos como fertilizantes e o aumento da disponibilidade de água para reúso.

Estudos desenvolvidos pelo Programa de Pesquisa em Saneamento Básico - PROSAB apresentados por Campos, 1999, enfatizam que em relação aos processos de disposição no solo, os receios referentes aos aspectos de saúde pública e proteção ambiental, são maximizados, talvez por ser uma alternativa ainda pouco difundida no Brasil, porém os riscos são semelhantes a qualquer outro sistema de tratamento de esgotos domésticos, podendo ser controlados mediante práticas que respeitem a capacidade natural do meio e obedeçam a limites e critérios estabelecidos para esta finalidade.

Assim posto, neste trabalho serão eventualmente comparados os resultados com estudos pretéritos que empregam a disposição no solo como pós-tratamento de reatores UASB, uma vez que, conforme menciona Kato et al (1999), estes preservam os nutrientes que podem ser aproveitados para finalidades produtivas para variadas culturas vegetais e a disposição no solo remove microrganismos patogênicos antes de alcançarem os corpos d'água.

Vale ressaltar que especialmente no caso de Populina a incidência de ovos de helmintos no esgoto bruto é excepcionalmente baixa, sendo inferior aos valores encontrados para efluentes tratados por reatores anaeróbios, conforme estudos desenvolvidos no PROSAB (Araújo et al, 1999), onde os valores observados nas contagens de ovos ficaram em média em 13 ovos/L, um número já superior aos valores encontrados no esgoto bruto em Populina.

\section{Pesquisa de ovos de helmintos}

A pesquisa de helmintos neste trabalho se deu pelo fato de eles possuíram ovos ou larvas cuja maturação se faz no solo, sendo chamados de geohelmintos.

Foram identificados ovos de Ascaris sp., ancilostomídeos e Enterobius sp. Em uma única ocasião foram encontrados ovos de Taenia sp. e Hymenolepis sp. no esgoto afluente.

A Tabela 2 apresenta o número de ovos viáveis de Ascaris sp., de ancilostomídeos e de Enterobius sp. encontrados no afluente e efluente da estação, nas três amostragens. 
Nos estudos desenvolvidos por Araújo et al, 2000, na disposição de esgotos no solo como pós-tratamento de reatores UASB, não se verificou a presença de ovos de helmintos no efluente da estação de tratamento.

A Tabela 3 mostra o número de ovos viáveis de Ascaris encontrados na superfície do solo (S) e a 30 centímetros de profundidade (30), assim como a localização desses pontos (distância do ponto de aplicação) e o tempo de secagem dos módulos correspondentes.

É possível notar que esses ovos foram encontrados em todos os pontos da superfície do solo, exceto no módulo com cinco dias de secagem. Esses ovos não foram encontrados no ponto controle (P5), pois este não recebe esgotos, está fora dos módulos de tratamento, mas apresenta as mesmas características do solo. A presença de ovos viáveis de Ascaris sp. no solo pode indicar um efeito cumulativo resultante de 24 horas de aplicação contínua do esgoto no módulo de tratamento.

Segundo Stien e Schwartzbrod (1990) os ovos de Ascaris sp. são muito resistentes às condiçôes ambientais externas, tornando-os os mais prováveis de serem encontrados viáveis em solos ou vegetais poluídos. Esses autores desenvolveram um trabalho experimental na França, onde estudaram o tempo de sobrevivência de ovos de Ascaris no solo e em vegetais irrigados com água contaminada. Os resultados mostraram que a sobrevivência é importante nos primeiros 20 dias, a partir do qual decresce rapidamente. A sobrevivência na superfície do solo ou a 10 centímetros de profundidade é dependente de dois fatores, principalmente: exposição ou proteção da luz solar direta (a porcentagem maior de ovos foi encontrada em solos sombreados) e tipo de solo e capacidade de retenção de umidade (solo arenoso elimina mais, pois tem menor capacidade de retenção de umidade). A viabilidade dos ovos foi duas vezes maior nas amostras profundas do que na superfície.

A Tabela 4 mostra o número de ovos de ancilostomídeos encontrados na superfície do solo (S) e a 30 centímetros de profundidade (30), assim como a localização desses pontos (distância do ponto de aplicação) e o tempo de secagem dos módulos correspondentes.

Nas três amostragens não foram encontrados ovos de ancilostomídeos no efluente tratado, embora tenham sido identificados no solo. Esses resultados levam a inferir que o solo parece ser capaz de reter os ovos e, portanto, diminuir a capacidade de movimentação dos mesmos.

Ovos de Enterobius sp. não foram encontrados no esgoto afluente e no efluente, mas foram encontrados no solo do sistema de tratamento, como mostra a Tabela 5, tanto na superfície do solo (S), quanto a $30 \mathrm{~cm}$ de profundidade (30).

A presença desses ovos no solo é bastante irregular e, em nenhuma ocasiāo, esses organismos foram encontrados no esgoto bruto ou no efluente da estação. Assim como os ovos de ancilostomídeos, ovos de Enterobius sp. também ficam retidos, principalmente na superfície do solo.

A seguir serão discutidos os resultados encontrados em função da distância do ponto de aplicação, profundidade do solo e tempo de secagem do módulo.

\section{a) Em relação à distância do ponto de aplicação}

Amostras foram coletadas a $20 \mathrm{e}$ a 50 metros de distância do ponto de aplicação. Os resultados mostraram que a concentração de ovos viáveis de Ascaris diminuiu com a distância do ponto de aplicação. Ovos de ancilostomídeos e Enterobius sp. seguiram a mesma tendência, exceto na terceira coleta. Este fato deverá ser verificado em pesquisas futuras.

Tabela 2 - Número de ovos viáveis de Ascaris sp., ancilostomídeos e de Enterobius sp. no afluente e efluente da ETE de Populina (ovos/L)

\begin{tabular}{ccccccc}
\hline $\begin{array}{c}\text { Data da } \\
\text { amostragem }\end{array}$ & \multicolumn{2}{c}{$\begin{array}{c}\text { Ovos viáveis de } \\
\text { Ascaris sp. }\end{array}$} & \multicolumn{2}{c}{ Ancilostomídeos } & \multicolumn{2}{c}{ Enterobius sp. } \\
& Afluente & Efluente & Afluente & Efluente & Afluente & Efluente \\
\hline $01 / 12 / 2003$ & 10 & 3 & 2 & 0 & 0 & 0 \\
$18 / 05 / 2004$ & 0 & 1 & 2 & 0 & 0 & 0 \\
$12 / 10 / 2004$ & 0 & 0 & 0 & 0 & 0 & 0 \\
\hline
\end{tabular}

À medida que o esgoto percorre o módulo de tratamento, ovos de helmintos vão ficando retidos na superfície do solo e, portanto, a 50 metros de distância do ponto de aplicação seria esperado um número menor de organismos. De maneira geral, isso aconteceu para os ovos pesquisados, os quais ocorreram em maior número a $20 \mathrm{~m}$ de distância do ponto de aplicação dos esgotos.

\section{b) Em relação à profundidade no solo}

De maneira geral, o número de organismos pesquisados foi sempre maior na superfície do que a 30 centímetros de profundidade no solo. Embora na superfície do solo os organismos deveriam sofrer os efeitos adversos do ambiente, como radiação solar e alta temperatura, um certo grau de umidade e a vegetação de cobertura poderiam fornecer condições de sobrevivência aos organismos. Os resultados mostram ainda que os organismos ficam retidos na camada mais superficial do terreno, o que protegeria o lençol freático da contaminação por helmintos.

Trabalhos anteriores mostraram uma diminuição de argila e um aumento de areia no solo entre 5 e 30 centímetros de profundidade (Paganini, 2001). O solo arenoso retém uma porcentagem menor de umidade, o que dificultaria a sobrevivência desses microrganismos, favorecendo a sua eliminação a 30 centímetros de profundidade.

\section{c) Em relação ao tempo de secagem do módulo}

No primeiro dia de secagem do módulo, ovos de helmintos foram encontrados em $70 \%$ das amostras. Amostras coletadas em módulos com cinco dias de secagem apresentaramse isentas de organismos e, portanto, nenhum ovo viável de Ascaris foi encontrado nesta situação. A porcentagem de umidade na superfície do solo foi de $28,40 \%$ na superfície e $10,15 \%$ a 30 centímetros de profundidade (Tabela 6), ou seja, nas condições deste estudo, a eliminação de parasitas foi satisfatória, podendo indicar que esses teores de umidade favorecem a eliminação de parasitas no solo.

$\mathrm{Na}$ terceira amostragem $(12 / 10 / 04)$, em que foram coletadas amostras de solo com 20 dias de secagem, apenas ovos de ancilostomídeos 
Tabela 3 - Número de ovos viáveis de Ascaris sp. no solo (ovos/g de solo) da ETE de Populina

\begin{tabular}{|c|c|c|c|c|c|}
\hline \multirow{2}{*}{$\begin{array}{l}\text { Dias de secagem } \\
\text { do módulo }\end{array}$} & \multirow{2}{*}{$\begin{array}{c}\text { Distância do } \\
\text { ponto de } \\
\text { aplicação }\end{array}$} & \multirow[t]{2}{*}{ Pontos } & \multicolumn{3}{|c|}{ Data da amostragem } \\
\hline & & & $01 / 12 / 03$ & $18 / 05 / 04$ & $12 / 10 / 04$ \\
\hline \multirow[t]{8}{*}{$1 \mathrm{dia}$} & $20 \mathrm{~m}$ & P1 (S) & 18 & & \\
\hline & & P1 (30) & 0 & & \\
\hline & & P3 (S) & & 5 & 13 \\
\hline & & P3 (30) & & 0 & 1 \\
\hline & $50 \mathrm{~m}$ & P2 (S) & 7 & & \\
\hline & & P2 (30) & 0 & & \\
\hline & & $\mathrm{P} 4(\mathrm{~S})$ & & 4 & 8 \\
\hline & & P4 (30) & & 1 & 5 \\
\hline \multirow[t]{2}{*}{5 dias } & $200 \mathrm{~m}$ & P6 (S) & & 0 & \\
\hline & & P6 (30) & & 0 & \\
\hline \multirow[t]{4}{*}{20 dias } & $20 \mathrm{~m}$ & P6 (S) & & & 3 \\
\hline & & P6 (30) & & & 7 \\
\hline & $50 \mathrm{~m}$ & P7 (S) & & & 2 \\
\hline & & P7 (30) & & & 1 \\
\hline \multicolumn{2}{|c|}{ Controle } & P5 (S) & 0 & 0 & 0 \\
\hline & & P5 (30) & 0 & 0 & 0 \\
\hline
\end{tabular}

Tabela 4 - Número de ovos de ancilostomídeos no solo da ETE de Populina (ovos/g peso seco)

\begin{tabular}{|c|c|c|c|c|c|}
\hline \multirow{2}{*}{$\begin{array}{c}\text { Dias de secagem } \\
\text { do módulo }\end{array}$} & \multirow{2}{*}{$\begin{array}{l}\text { Distância do } \\
\text { ponto de } \\
\text { aplicaçãa }\end{array}$} & \multirow[t]{2}{*}{ Pontos } & \multicolumn{3}{|c|}{ Data da amostragem } \\
\hline & & & $01 / 12 / 03$ & $18 / 05 / 04$ & $12 / 10 / 04$ \\
\hline \multirow[t]{8}{*}{1 dia } & $20 \mathrm{~m}$ & P1 (S) & 7 & & \\
\hline & & P1 (30) & 0 & & \\
\hline & & P3 (S) & & 4 & 0 \\
\hline & & P3 (30) & & 0 & 0 \\
\hline & $50 \mathrm{~m}$ & P2 (S) & 4 & & \\
\hline & & P2 (30) & 0 & & \\
\hline & & $\mathrm{P} 4(\mathrm{~S})$ & & 2 & 8 \\
\hline & & P4 (30) & & 0 & 1 \\
\hline \multirow[t]{2}{*}{5 dias } & $20 \mathrm{~m}$ & P6 (S) & & 0 & \\
\hline & & P6 (30) & & 0 & \\
\hline \multirow[t]{4}{*}{20 dias } & $20 \mathrm{~m}$ & P6 (S) & & & 0 \\
\hline & & P6 (30) & & & 0 \\
\hline & $50 \mathrm{~m}$ & P7 (S) & & & 0 \\
\hline & & P7 (30) & & & 1 \\
\hline \multicolumn{2}{|c|}{ Controle } & P5 (S) & 0 & 0 & 0 \\
\hline & & P5 (30) & 0 & 0 & 0 \\
\hline
\end{tabular}


não foram identificados no ponto 6 e no ponto 7 (superfície), os demais organismos foram encontrados nos outros pontos. Ovos de Enterobius sp. foram encontrados em maior número nos pontos 6 e 7 do que nos pontos $3 \mathrm{e}$ 4 (primeiro dia de secagem do módulo). Ovos viáveis de Ascaris foram encontrados nos dois pontos amostrados e na superfície e a 30 centímetros de profundidade.

A sobrevivência de ovos e larvas de helmintos está associada, entre outros fatores, com a porcentagem de umidade do solo. Alguns microrganismos persistem mais tempo em solos úmidos do que em secos (Yates e Yates, 1991 citado por Pinilla, 1998). De acordo com Pinilla (1998), a umidade é o parâmetro que mais influencia a eliminação de microrganismos em qualquer tipo de solo.

A Tabela 6 mostra a porcentagem de umidade em todos os pontos amostrados. Esses resultados podem explicar a viabilidade de ovos de Ascaris no módulo com 20 dias de secagem.

A porcentagem de umidade no P6 (S) da coleta do dia 18/05/04 é bastante inferior à encontrada no P6 (S) e P7 (S) da coleta do dia $12 / 10 / 04$. O teor de umidade, encontrado no solo com cinco dias de secagem, não favoreceu a sobrevivência de ovos e larvas.

Por outro lado, os teores mais elevados de umidade na superfície do ponto 6 e do ponto 7 (coleta de $12 / 10 / 04$ ) parecem favorecer a sobrevivência de ovos. Ovos viáveis de Ascaris foram encontrados na superfície e a 30 centímetros de profundidade nestes pontos.

O módulo IV é o que apresenta melhor distribuição do fluxo (Paganini, 2001)e na oportunidade das coletas não foram identificados empoçamentos neste módulo. De acordo com moradores da região, ocorreram chuvas nos dias que antecederam a coleta. A alta umidade, portanto, pode estar associada com chuvas e/ou com a altura da vegetação de cobertura, um pouco mais alta que em outros módulos, o que pode favorecer a sobrevivência de organismos devido à proteção contra os raios solares e os efeitos da dessecação.

Esses resultados estão de acordo com o trabalho de Stien e Schwartzbrod (1990), que encontraram maior porcentagem de ovos em solos sombreados e em solos argilosos devido a este
Tabela 5 - Número de ovos de Enterobius sp. no solo da ETE de Populina (ovos/g peso seco)

\begin{tabular}{|c|c|c|c|c|c|}
\hline \multirow{2}{*}{$\begin{array}{l}\text { Dias de secagem } \\
\text { do módulo }\end{array}$} & \multirow{2}{*}{$\begin{array}{c}\text { Distância do } \\
\text { ponto de } \\
\text { aplicação }\end{array}$} & \multirow[t]{2}{*}{ Pontos } & \multicolumn{3}{|c|}{ Data da amostragem } \\
\hline & & & $01 / 12 / 03$ & $18 / 05 / 04$ & $12 / 10 / 04$ \\
\hline \multirow[t]{8}{*}{1 dia } & $20 \mathrm{~m}$ & P1 (S) & 2 & & \\
\hline & & P1 (30) & 0 & & \\
\hline & & P3 (S) & & 0 & 6 \\
\hline & & P3 (30) & & 0 & 1 \\
\hline & $50 \mathrm{~m}$ & P2 (S) & 0 & & \\
\hline & & P2 (30) & 1 & & \\
\hline & & P4 (S) & & 0 & 8 \\
\hline & & P4 (30) & & 0 & 0 \\
\hline \multirow[t]{2}{*}{5 dias } & $20 \mathrm{~m}$ & P6 (S) & & 0 & \\
\hline & & P6 (30) & & 0 & \\
\hline \multirow[t]{4}{*}{20 dias } & $20 \mathrm{~m}$ & P6 (S) & & & 15 \\
\hline & & P6 (30) & & & 3 \\
\hline & $50 \mathrm{~m}$ & P7 (S) & & & 19 \\
\hline & & P7 (30) & & & 6 \\
\hline \multirow{2}{*}{\multicolumn{2}{|c|}{ Controle }} & P5 (S) & 0 & 0 & 1 \\
\hline & & P5 (30) & 0 & 0 & 1 \\
\hline
\end{tabular}

Tabela 6 - Porcentagem de umidade (\%) do solo em todos os pontos de coleta

\begin{tabular}{|c|c|c|c|c|c|}
\hline \multirow{2}{*}{$\begin{array}{c}\text { Dias de secagem } \\
\text { do módulo }\end{array}$} & \multirow{2}{*}{$\begin{array}{c}\text { Distância do } \\
\text { ponto de } \\
\text { aplicação }\end{array}$} & \multirow[t]{2}{*}{ Pontos } & \multicolumn{3}{|c|}{ Data da amostragem } \\
\hline & & & $01 / 12 / 03$ & $18 / 05 / 04$ & $12 / 10 / 04$ \\
\hline \multirow[t]{8}{*}{$1 \mathrm{dia}$} & $20 \mathrm{~m}$ & P1 (S) & 77,51 & & \\
\hline & & P1 (30) & 16,79 & & \\
\hline & & P3 (S) & & 72,60 & 77,80 \\
\hline & & P3 (30) & & 14,70 & 17,05 \\
\hline & $50 \mathrm{~m}$ & P2 (S) & 53,12 & & \\
\hline & & P2 (30) & 15,43 & & \\
\hline & & $\mathrm{P} 4(\mathrm{~S})$ & & 29,15 & 74,05 \\
\hline & & P4 (30) & & 14,25 & 15,50 \\
\hline \multirow[t]{2}{*}{5 dias } & $20 \mathrm{~m}$ & P6 (S) & & 28,40 & \\
\hline & & P6 (30) & & 10,15 & \\
\hline \multirow[t]{4}{*}{20 dias } & $20 \mathrm{~m}$ & P6 (S) & & & 48,45 \\
\hline & & P6 (30) & & & 8,10 \\
\hline & $50 \mathrm{~m}$ & P7 (S) & & & 56,90 \\
\hline & & P7 (30) & & & 6,25 \\
\hline \multirow{2}{*}{\multicolumn{2}{|c|}{ Controle }} & P5 (S) & 13,25 & 12,30 & 12,67 \\
\hline & & P5 (30) & 10,44 & 10,05 & 10,30 \\
\hline
\end{tabular}


ter maior capacidade de retenção de umidade. Na estação de tratamento de esgotos de Populina o solo módulos de tratamento é mais argiloso entre 0 a 5 centímetros de profundidade (Paganini, 2001).

Araújo et al (2000) estudaram a eficiência de um sistema de disposição de esgotos no solo, por escoamento superficial, como pós-tratamento de efluentes de reatores UASB. O sistema de aplicação de esgotos no solo constava de três rampas com área unitária igua la $75 \mathrm{~m}^{2}$ (25 metros de comprimento por 3 metros de largura), com declividade igual a $4 \%$. Uma pequena parcela do efluente do reator UASB foi distribuída nas cabeceiras das rampas, por meio de tubos de PVC perfurados. O esgoto, depois de escoar pelo solo, era encaminhado a três caixas de passagem que recolhiam o efluente de cada uma das rampas. Para análises parasitológicas foram coletadas amostras compostas do esgoto bruto, do efluente do reator UASB e do efluente das rampas de aplicação superficial no solo. As análises do efluente do reator UASB apresentaram uma média de 13 ovos/L de helmintos, tendo sido identificados ovos de ancilostomídeos, Ascaris lumbricoides, Enterobius vermicularis, Hymenolepis sp. e Taenia sp., sendo os ovos de A. lumbricoides e de ancilostomídeos os que apresentaram freqüências de ocorrência superiores às dos demais organismos. No efluente final das rampas de aplicação superficial não foram observados ovos de helmintos. Os autores concluíram que o sistema de escoamento superficial no solo funcionou de forma bastante promissora como pós-tratamento de reatores UASB, com uma excelente remoção de ovos de helmintos.

\section{Pesquisa de Salmonella sp.}

Os resultados das pesquisas de ocorrência de Salmonella sp. no afluente e efluente da ETE Populina encontramse na Tabela 7 e foram expressos como presença ou ausência de Salmonella sp., de acordo com o método utilizado.

$\mathrm{Na}$ Tabela 8 são apresentados os resultados das pesquisas de ocorrência de Salmonella sp. nos módulos de tratamento da estação.

Os resultados mostraram a presença de Salmonella sp. no esgoto bruto e efluente nas duas últimas coletas. Não houve um padrão de distribuição desta bactéria no solo do sistema, sendo en-

Tabela 7 - Ocorrência de Salmonella sp. no afluente e efluente da ETE Populina

\begin{tabular}{cccc}
\hline Esgoto & \multicolumn{3}{c}{ Data } \\
& $01 / 12 / 2003$ & $18 / 5 / 2004$ & $12 / 10 / 2004$ \\
\hline Afluente & Asente & Presente & Presente \\
Efluente & Ausente & Presente & Presente \\
\hline
\end{tabular}

Tabela 8 - Ocorrência de Salmonella sp. no solo da ETE Populina

\begin{tabular}{|c|c|c|c|c|c|}
\hline \multirow{2}{*}{$\begin{array}{c}\text { Dias de secagem } \\
\text { do módulo }\end{array}$} & \multirow{2}{*}{$\begin{array}{c}\text { Distância do } \\
\text { ponto de } \\
\text { aplicação }\end{array}$} & \multirow[t]{2}{*}{ Pontos } & \multicolumn{3}{|c|}{ Data da amostragem } \\
\hline & & & $01 / 12 / 03$ & $18 / 05 / 04$ & $12 / 10 / 04$ \\
\hline \multirow[t]{8}{*}{$1 \mathrm{dia}$} & $20 \mathrm{~m}$ & P1 (S) & Ausente & & \\
\hline & & P1 (30) & Ausente & & \\
\hline & & P3 (S) & & Presente & Ausente \\
\hline & & P3 (30) & & Ausente & Presente \\
\hline & $50 \mathrm{~m}$ & P2 (S) & Ausente & & \\
\hline & & P2 (30) & Ausente & & \\
\hline & & P4 (S) & & Ausente & Presente \\
\hline & & P4 (30) & & NR & Presente \\
\hline \multirow[t]{2}{*}{5 dias } & $20 \mathrm{~m}$ & P6 (S) & & Presente & \\
\hline & & P6 (30) & & Ausente & \\
\hline \multirow[t]{4}{*}{20 dias } & $20 \mathrm{~m}$ & P6 (S) & & & Ausente \\
\hline & & P6 (30) & & & NR \\
\hline & $50 \mathrm{~m}$ & P7 (S) & & & Presente \\
\hline & & P7 (30) & & & NR \\
\hline \multirow{2}{*}{\multicolumn{2}{|c|}{ Controle }} & P5 (S) & Ausente & Presente & Ausente \\
\hline & & P5 (30) & Ausente & Ausente & Ausente \\
\hline
\end{tabular}

$\mathrm{NR}$ = não realizado

contrada tanto na superfície (S) quanto a 30 centímetros de profundidade (30) e nos solos no primeiro dia de secagem do módulo e em solos com 5 e 20 dias de secagem.

Salmonella sp. foi detectada em pontos com teor de umidade variando entre $15,5 \%$ e $72,6 \%$. Esses resultados mostram que esta bactéria, nas condições deste trabalho, não foi afetada por baixos teores de umidade.

Os resultados deste trabalho estão de acordo com o trabalho de Parker e Mee (1992), os quais compararam a sobrevivência de Salmonella adelaide e de coliformes fecais em solos arenosos. Os resultados mostraram que a porcentagem de umidade não parecia ser um fator limitante na sobrevivência destas bactérias. Somente foi observada uma porcentagem menor de Salmonella adelaide e de coliformes quando a umidade foi menor que 5\%. De acordo com estes resultados, os autores concluíram que a umidade, pelo menos neste tipo de solo (arenoso), não influenciou a sobrevivência desses organismos.

O trabalho desenvolvido por Ceballos et al (2003) mostrou que Salmonella sp e Listeria são mais persistentes no meio ambiente do que os indicadores bacterianos. Para Plachá e col. (2001), um estudo de sobrevivência de Salmonella typhimurium no solo mostrou que esta bactéria foi afetada pela temperatura. Esta bactéria sobreviveu por 85 dias nas estações mais frias (outono/inverno) e por 26 dias no verão. A alta temperatura e a pouca umidade do solo parecem ter favorecido a eliminação de Salmonella typhimurium.

O gênero Salmonella é resistente às condições ambientais desfavoráveis e é capaz de se multiplicar fora de seus hospedeiros (Strauss, 1991). Para Marecos do Monte e col. (1996) os helmintos são o grupo de maior risco para 
a saúde pública na prática de irrigação com esgotos, seguido pelo grupo das bactérias patogênicas, em especial, o gênero Salmonella. Esta é considerada a mais importante das bactérias patogênicas em relação a aplicação de esgoto ao solo (Environment Canada 1984). Arridge e col. (1995) sugerem um monitoramento constante da qualidade do efluente para Salmonella, principalmente em regiōes endêmicas.

A constatação da presença de Salmonella sp. no efluente leva a necessidade de um monitoramento da qualidade microbiológica do efluente e do corpo receptor. Novos estudos devem ser realizados quanto a sobrevivência desta bactéria no solo.

\section{Determinação de coliformes totais e $E$. coli}

A determinação de coliformes totais e $E$. coli foi realizada apenas nas amostras de esgoto afluente e efluente. Os resultados das análises de coliformes totais e $E$. coli no afluente e no efluente da estação estão apresentados na Tabela 9.

Os resultados obtidos neste trabalho foram muito parecidos nas três coletadas realizadas, tanto para o esgoto afluente quanto para o efluente. Este apresentou redução de 1 unidade de log comparado ao esgoto bruto.

Esses valores são semelhantes aos obtidos anteriormente no efluente da estação, o qual apresentou uma densidade de coliformes totais de $1,3 \times 10^{8} \mathrm{NMP} / 100 \mathrm{~mL}$ e coliformes fecais de $2,2 \times 10^{7} \mathrm{NMP} / 100 \mathrm{~mL}$. Naquela oportunidade, conforme demonstrava a pesquisa, o sistema já estava trabalhando com sobrecarga, verificando-se a presença de coliformes totais e fecais no corpo receptor até 500 metros a jusante do lançamento dos efluentes da estação de tratamento (Paganini, 2001).Estudos e pesquisas buscam associar a prática de disposição de esgotos ou efluentes no solo com o aumento de incidência de doenças em populações expostas. A partir dessa associação fala-se em riscos à saúde devidos principalmente à presença de microrganismos patogênicos presentes nos esgotos brutos ou insuficientemente tratados.

Primeiramente, faz-se necessário definir os conceitos de riscos potenciais e riscos reais. Os riscos potenciais referem-se simplesmente à presença de um agente patogênico no solo ou na

Tabela 9 - Coliformes totais e E. coli no afluente e efluente da ETE de Populina (NMP/I00mL)

\begin{tabular}{ccccc}
\hline \multirow{2}{*}{$\begin{array}{c}\text { Data da } \\
\text { amostragem }\end{array}$} & \multicolumn{2}{c}{ Coliformes totais } & \multicolumn{2}{c}{ E. coli } \\
& Afluente & Efluente & Afluente & Efluente \\
\hline $01 / 12 / 2003$ & $>2,4 \times 10^{8}$ & $3,8 \times 10^{7}$ & $2,4 \times 10^{8}$ & $1,9 \times 10^{7}$ \\
$18 / 05 / 2004$ & $>2,4 \times 10^{8}$ & $3,7 \times 10^{7}$ & $2,0 \times 10^{8}$ & $1,9 \times 10^{7}$ \\
$12 / 10 / 2004$ & $2,0 \times 10^{8}$ & $6,2 \times 10^{7}$ & $1,1 \times 10^{8}$ & $2,4 \times 10^{7}$ \\
\hline
\end{tabular}

cultura. Os riscos reais são baseados em evidências epidemiológicas que demonstram um aumento de incidência de doenças em populaçóes expostas ou um agravo à saúde. A simples detecção de um determinado agente patogênico em esgotos, solos ou culturas não significa o imediato desenvolvimento da doença, pois existem fatores característicos dos microrganismos, dos hospedeiros e fatores extrínsecos que atuam como barreiras de proteção.

Alguns fatores característicos dos microrganismos são: comportamento no meio (latência, persistência, capacidade de sobrevivência no meio ambiente e multiplicação no meio ambiente); dose infectiva (número, em média, de microrganismos necessários para provocar uma infecção em uma pessoa); imunidade que proporcionam e rotas de transmissão prioritárias (Andrade Neto, 1997).

Alguns fatores característicos dos hospedeiros são: imunidade natural ou adquirida; idade; condiçôes gerais de saúde, como nível de nutrição; hábitos culturais e padrões higiênicos.

Podem ser citados como fatores extrínsecos aos microrganismos e aos hospedeiros, que atuam como barreiras de proteção: o tratamento dos esgotos; a capacidade do solo em afetar a sobrevivência dos microrganismos, caso estes cheguem ao solo; métodos apropriados de disposição dos esgotos; escolha de culturas adequadas; medidas de proteção para reduzir o contato do indivíduo com o esgoto ou efluente.

Portanto, para que um microrganismo presente no esgoto cause uma doença quando este é disposto no solo, ele precisa: sobreviver ao tratamento dos esgotos, sobreviver às condições ambientais desfavoráveis do solo, manter um certo nível de dose infectiva, entrar em contato com o hospedeiro e que este seja susceptível. Tem-se em um extremo o risco potencial (presença do microrganismo) e no outro o risco real (desenvolvimento da doença) e entre esses extremos as barreiras de proteção (OMS, 1989). Geralmente, o risco real de provocar doenças é muito inferior ao risco potencial, caracterizado pela simples constatação da presença do microrganismo (Hespanhol, 2003).

Nos sistemas de tratamento por disposição superficial no solo, algumas medidas de proteção dos grupos de risco devem ser tomadas como: isolamento e sinalização da estação de tratamento por disposição no solo; utilização de equipamentos de proteção individual para os trabalhadores da estação de tratamento, como o uso de calçados e luvas; desenvolver campanhas de educação sanitária, visando aumentar os padrōes de higiene pessoal e alimentar e monitorar a qualidade do corpo receptor, quanto ao uso da água a jusante.

Os dados obtidos nas três amostragens realizadas resultaram em considerações e recomendaçōes, as quais poderão orientar e conduzir trabalhos futuros mais aprofundados.

Diante do exposto, recomendase:

- A continuidade dos estudos na Estação de Tratamento de Esgotos de Populina a fim de compreender a movimentação e sobrevivência de ovos e larvas de helmintos no solo.

- A realização de novas pesquisas de Salmonella sp. objetivando conhecer a capacidade deste método de tratamento para remoção desse organismo.

- A execução de um monitoramento da qualidade do efluente e do corpo receptor quanto à presença de Salmonella sp., coliformes totais e E. coli.

- A manutenção do corte da vegetação de cobertura, pois a altura desta pode influenciar a sobrevivência de ovos e larvas de helmintos, à medida que proporciona sombreamento do solo e a manutenção de um certo grau de umidade. 


\section{CONCLUSÕES}

A Estação de Tratamento de Esgotos de Populina é um campo ímpar de trabalho e pesquisas, visto que está em funcionamento há mais de 20 anos e, mesmo operando com sobrecarga, ainda atua efetivamente como barreira sanitária, conforme os resultados apresentados neste trabalho, em relação a remoção dos organismos pesquisados.

A partir da análise dos resultados obtidos é possível concluir que:

- O sistema foi capaz de reduzir o número de ovos de helmintos no efluente final em relação ao afluente.

- O comprimento dos módulos de tratamento na Planta de Populina foi adequado e suficiente para a retenção de ovos de helmintos, visto que o número de organismos encontrados a 50 metros de distância do ponto de aplicação foi menor do que a 20 metros.

- Ovos de helmintos são encontrados em maior número na superfície do solo.

- Embora as coletas tenham sido realizadas em pontos diferentes, os resultados apresentam indícios de que a umidade exerce certa influência na viabilidade de ovos de Ascaris, o que pode ser verificado na coleta de solo no módulo com 20 dias de secagem, pois mesmo estando sem receber esgotos, houve um aumento de umidade em decorrência de chuvas.

- Salmonella sp. foi encontrada no afluente e no efluente da estação de tratamento e em diversos pontos nos módulos da ETE. Não houve um padrão de distribuição desta bactéria no solo da estação.

- O sistema não apresentou uma remoção satisfatória de coliformes totais e E. coli.

\section{REFERÊNCIAS}

ABU-ZEID, K.M. Recent trends and developments: reuse of wastewater in agriculture. Environmental Management and Health. 9(2): 79-89. 1998.

AMAHMID, O., BOUHOUM, K. Health effect of urban wastewater reuse in a peri-urban area in Morocco. Environmental Management and Health. 11(3): 263-269. 2000.

ARAÚJO, R.A. Eficiência de algumas estações de tratamento de esgotos de Feira de Santana na remoção de carga orgânica, coliformes, helmintos e protozoários e situações de risco de usuários a jusante do lançamento. São Paulo; [Tese de Doutorado - Faculdade de Saúde Pública da USP]. 2003.

ARAUJO, G.C. et al. Avaliação de um sistema de escoamento superficial de esgotos no solo aplicado ao pós-tratamento de efluentes de reatores UASB. In: CAMPOS, J.R. (Coord.). Tratamento de esgotos sanitários por processos anaeróbio e disposiçáo controlada no solo - Coletânea de Trabalhos Técnicos. Projeto PROSAB. São Carlos, p.31-45. 2000.

AYRES, R.M, MARA, D.D. Análises de águas residuales para su uso em agricultura: Manual de técnicas parasitológicas y bacteriológicas de laboratório. Organización Mundial de la Salud. Ginebra; 1997.

BASTOS, R.K.X. Utilização agrícola de esgotos sanitários. Viçosa: Universidade Federal de Viçosa/ABES; 1999.

CAMPOS, J.R. (Coord.). Tratamento de esgotos Sanitários por processo anaeróbio e disposição controlada no solo. Projeto PROSAB. São Carlos, 1999.

CEBALLOS, B.S.O. et al. Microbiological aspects of an urban river used for unrestricted irrigation in the semi-arid region of north east Brazil. Water Science and Technology. 47(3): 51-57. 2003.

CETESB NORMA TÉCNICA - L5.218 - Salmonella - isolamento e identificação. São Paulo, 1993.

CORAUCCI FILHO, B. et al. Tecnologia do tratamento de águas residuais no solo: infiltração rápida, irrigação e escoamento superficial. In: Campos $\mathrm{JR}$, coordenador. Tratamento de esgotos sanitários por processo anaeróbio e disposição controlada no solo. Rio de Janeiro: ABES; 1999.

[EPA] ENVIRONMENTAL PROTECTION AGENCY. Wastewater treatment/disposal fos small communities (manual - EPA). Washington (DC); 1992a.

[EPA] ENVIRONMENTAL PROTECTION AGENCY. Environmental Regulations and Technology: Control of pathogens and vector attraction in sewage sludge (including domestic septage - under 40 CFR Part 503). Washington (DC); $1992 \mathrm{~b}$.

FRIEDEL, J.K. et al. Effects of long-term waste water irrigation on soil organic matter, soil microbial biomass and its activities in central Mexico. Biol Fertil Soils; 31: 414-421. 2000.

GOVERNO DO ESTADO DE SÃO PAULO/ SECRETARIA DE ESTADO DO MEIO AMBIENTE. Informaçôes básicas para o planejamento ambiental. São Paulo: 2002.

KATO, M. T., et al. Configuraçôes de reatores anaeróbios. In: Tratamento de esgotos Sanitários por processo anaeróbio e disposição controlada no solo. Projeto PROSAB. São Carlos, 1999

ORON, G. et al. Wastewater treatment, renovation and reuse for agricultural irrigation in small communities. Agricultural Water Management; 38: 223-234. 1999.

PAGANINI, W.S. Reuso de água na agricultura. In: Mancuso, PCS, Santos HF, editores. Reúso de água. São Paulo: Manole; p. 339-401. 2003.

PAGANINI, W.S. Efeitos da disposição de esgotos no solo. São Paulo; [Tese de Doutorado - Faculdade de Saúde Pública da USP]. 2001.

PARKER, W., MEE, B. Survival of Salmonella Adelaide and fecal coliforms in coarse sands of the Swan coastal plain, Western Australia. Applied and Environmental Microbiology; 43: 981-996. 1992.
PINILLA, C.C. Indicadores de contaminación fecal em la reutilización de agua residual regenerada en suelos. Barcelona; [Título de Doctor-Facultad de Biologia Universidad de Barcelona]. 1998.

PLACHÁ, I. et al. The effect os summer and winter seasons on the survival of Salmonella typhimurium and indicator micro-organisms during the storage of solid fraction of pig slurry. Journal of Applied Microbiology; 91: 1036-1043. 2001.

SANTAMARÍA, J., TORANZOS, G.A. Enteric pathogens and soil: a short review. Int Microbiol; 6: 5-9. 2003

STIEN, J.L., SCHWARTZBROD, J. Experimental contamination of vegetables with helminth eggs. Water Science and Technology; 22(9): 51-57. 1990.

TERADA, M., PAGANINI, W.S., ZUCCOLO, A.C.F. Tratamento de esgotos domésticos por disposição no solo com utilização de gramíneas. Revista DAE; 45: 249-254. 1985.

VON SPERLING, M. Introdução à qualidade das águas e ao tratamento de esgotos. Belo Horizonte: Universidade Federal de Minas Gerais; 1996.

Endereço para correspondência:

Adriana de Souza Cavinatto
Departamento de Saúde
Ambiental
Faculdade de Saúde Pública
Universidade de São Paulo
Av. Dr. Arnaldo, 7 I5
OI246-904 São Paulo - SP - Brasil
Tel: (I I) 3388-6489
E-mail: adrianas@cetesbnet.sp.gov.br

